\title{
Evaluation of Push-out Bond Strength of a Resin Sealer to Dentin after a Final Flush of Three Irrigants
}

\author{
Shubha Choudhury ${ }^{1}$, Sunita Shivanand ${ }^{2}$, Anand C Patil ${ }^{3}$, Sneha A Patil ${ }^{4}$, Preeti K Doddwad ${ }^{5}$, Chetan Patil ${ }^{6}$
}

\begin{abstract}
Aim: To evaluate the push-out bond strength of resin-based sealer to root dentin after a final flush of three different irrigants.

Materials and methods: Thirty extracted human mandibular premolars were sectioned $4 \mathrm{~mm}$ below the cement-enamel junction and 60 horizontal disks of $2 \mathrm{~mm}$ from middle one-third of the root were prepared. The disks were immersed in $3 \%$ sodium hypochlorite for 1 minute, and after drying the disks, they were finally flushed with the following irrigants: group I-Chitosan solution, group II-Morinda citrifolia juice (MCJ), and group III-ethylenediaminetetraacetic acid (EDTA). The disks were filled with AH Plus sealer, and after 7 days, the disks were subjected to push-out bond strength using a universal testing machine.

Results: EDTA had the highest push-out bond strength followed by MCJ and then chitosan.

Conclusion: Chitosan and MCJ can be used as alternative irrigants as a final flush during the cleaning and shaping of the root canals.

Clinical significance: EDTA, chitosan solution, and MCJ are efficient in smear layer removal which thereby increases better sealer penetration and prevents the dislocation of obturating materials.

Keywords: Bond strength, Irrigants, Smear layer.

The Journal of Contemporary Dental Practice (2020): 10.5005/jp-journals-10024-2869
\end{abstract}

\section{INTRODUCTION}

Microflora within the pulp canal space can be reduced through chemomechanical procedures. The canal preparation generates an indeterminate smear layer on the dentin, which enhances colonization of microorganisms and also hinders the effect of irrigants and medicaments. ${ }^{1}$ It also impedes with the sealer bonding and penetration, thus compromising the seal post obturation. ${ }^{2}$

Eliminating the smear layer is of utmost importance. Various chemical irrigants are used during chemomechanical preparation to disinfect the pulp space and to remove smear layer. It has been studied that the interlocking of the sealer into the tubular dentin after the elimination of smear layer enhances displacement of obturating materials. ${ }^{3}$ The increased bond strength of a sealer from radicular dentin through micro-mechanical retention or frictional resistance is beneficial to maintain the integrity of the dentin-sealer interface.

Ethylenediaminetetraacetic acid (EDTA) is the most extensively used chelator. It acts on the inorganic portion of root canal dentin. It reacts with calcium ions of dentine resulting in calcium chelation, further decalcifying the dentine at approximate depths of 20 to 30 micron within 5 minutes. ${ }^{4}$ However, various ill effects of EDTA such as dentin erosion, which depends on the concentration and duration of application and damages the periapical area, is a matter of concern. Hence, the requirement of a biocompatible agent as a chelator is the need of the hour.

Chitosan, a natural polysaccharide obtained from the deacetylation of chitin which is found in crab and shrimp shells, has many applications due to its benefits such as biocompatibility, biodegradability, and bioadhesion. ${ }^{5}$ It also shows a remarkable chelating capacity for different metal ions because of its acidic $\mathrm{pH}$. The antifungal effect of a $2 \%$ chitosan gel containing $0.1 \%$ chlorhexidine against Candida albicans has been demonstrated, and its addition to calcium hydroxide paste as an intracanal
${ }^{1}$ Private Consultant, MDS Conservative Dentistry and Endodontics, Bengaluru, Karnataka, India

${ }^{2-5}$ Department of Conservative Dentistry and Endodontics, KLE's VK Institute of Dental Sciences, KAHER, Belagavi, Karnataka, India

${ }^{6}$ Department of Conservative Dentistry and Endodontics, Maratha Mandal Dental College, Belagavi, Karnataka, India

Corresponding Author: Sunita Shivanand, Department of Conservative Dentistry and Endodontics, KLE's VK Institute of Dental Sciences, KAHER, Belagavi, Karnataka, India, Phone: +91 9743101888, e-mail: drsunitamay24@gmail.com

How to cite this article: Choudhury S, Shivanand S, Patil AC, et al. Evaluation of Push-out Bond Strength of a Resin Sealer to Dentin after a Final Flush of Three Irrigants. J Contemp Dent Pract 2020;21(9): 982-985.

Source of support: Nil

Conflict of interest: None

medication has been proved to promote prolonged calcium ion release. ${ }^{6,7}$

Morinda citrifolia is a medicinal plant used for over 2,000 years by Polynesians. Commercially called as Noni, the fruit contains polysaccharides, scopoletin, vitamins, and minerals. It contains antibacterial compound L-asperuloside with alizarin. It has many therapeutic effects such as antimicrobial and anti-inflammatory and is an immune enhancer. ${ }^{8}$

Previous studies have reported the efficacy of chitosan and M. citrifolia juice (MCJ) for the elimination of the smear layer only. There is a lack of literature on the elimination of smear layer and push-bond strength of $\mathrm{AH}$ Plus sealer to dentin after a final rinse of chitosan and MCJ.

Hence, this study aims to evaluate and compare the push-out bond strength of AH Plus sealer to dentin after a final flush with $0.2 \%$ chitosan, $6 \% \mathrm{MCJ}$, and $17 \%$ EDTA.

(0) The Author(s). 2020 Open Access This article is distributed under the terms of the Creative Commons Attribution 4.0 International License (https://creativecommons. org/licenses/by-nc/4.0/), which permits unrestricted use, distribution, and non-commercial reproduction in any medium, provided you give appropriate credit to the original author(s) and the source, provide a link to the Creative Commons license, and indicate if changes were made. The Creative Commons Public Domain Dedication waiver (http://creativecommons.org/publicdomain/zero/1.0/) applies to the data made available in this article, unless otherwise stated. 


\section{Materials and Methods}

\section{Irrigant Preparation}

\section{Chitosan Solution Preparation ${ }^{9}$}

- To prepare $0.2 \%$ chitosan solution, $0.2 \mathrm{~g}$ of chitosan (Panvo Organics Limited, India) was diluted in $100 \mathrm{~mL}$ of $1 \%$ acetic acid, and the solution was stirred with a magnetic stirrer continuously for 2 hours.

\section{Morinda citrifolia Juice Preparation}

- To prepare $6 \%$ MCJ solution, $6 \mathrm{~mL}$ of commercial $100 \%$ MCJ (DIVINE NONI Nutraceuticals product) was diluted with $96 \mathrm{~mL}$ of distilled water.

Thirty extracted human permanent mandibular premolars were stored in $0.1 \%$ thymol solution. Teeth were then sectioned transversally $4 \mathrm{~mm}$ below the cement-enamel junction to provide sixty 2-mm-thick dentin disks from the middle one-third of the roots that were then mounted in acrylic resin. The canal space of each disk was prepared using a Gates Glidden drill no. 2 (Mani). Dentin disks were immersed in $1 \mathrm{~mL}$ of $3 \%$ sodium hypochlorite for 1 minute to simulate the irrigation during root canal preparation and then, per the test irrigants, the disks were randomly divided into three experimental groups $(n=20)$ as follows:

- Group I $(n=20): 1 \mathrm{~mL}$ of $0.2 \%$ chitosan solution for 1 minute,

- Group II $(n=20): 1 \mathrm{~mL}$ of $6 \%$ MCJ for 1 minute, and

- Group III $(n=20): 1 \mathrm{~mL}$ of $17 \%$ EDTA solution (CANALARGE; AMMDENT) for 1 minute.

After dentin treatment, standardized pulp spaces were dried with paper points and filled with AH Plus sealer. Specimens were incubated at $37^{\circ} \mathrm{C}$ in a humidifier for 7 days.

\section{Push-out Test}

The sealer was loaded with a 2-mm-diameter cylindrical stainlesssteel plunger. Loading was performed on a universal testing machine(TUE-C-400; Fine Spavy Associates \& Engineers Pvt. Ltd) at a speed of $1.2 \mathrm{~mm} /$ minute until debonding occurred (Fig. 1).

The bond strength value in megapascals ( $\mathrm{MPa}$ ) was computed by dividing the maximum load needed to dislodge the sealer by the interfacial area.

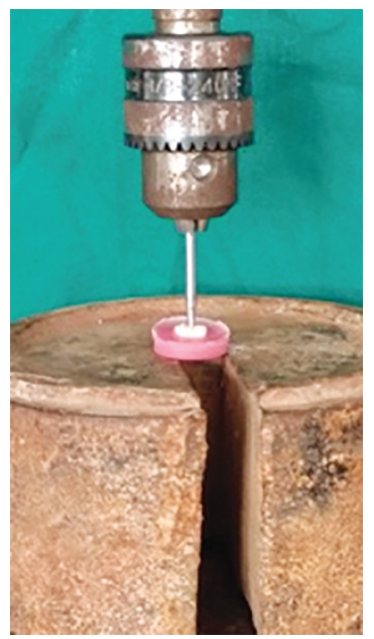

Fig. 1: Loading of the sealer with a 2-mm-diameter cylindrical stainlesssteel plunger. Loading was performed on a universal testing machine
Push-out bond strength $(\mathrm{MPa})=$ maximum load at which dislodgement is seen in surface area.

\section{Statistical Analysis}

Data obtained were analyzed statistically using one-way analysis of variance test to compare the mean bond strength of all the three groups. The intergroup comparison was done using the post hoc test (SPSS Software, Version 13.0, Chicago, IL).

\section{Results}

The result showed a statistically significant ( $p$ value $<0.001$ ) difference between all the three groups.

Comparison of mean push-out bond strength of three groups are as follows: EDTA showed significantly highest push-out bond strength than MCJ and chitosan solution ( $p$ value $<0.001$ ). The statistical ranking of push-out bond strength values is as follows: EDTA with mean push-out bond strength of $17.07 \mathrm{MPa}$, MCJ with 15.08 MPa, and chitosan solution with $12.12 \mathrm{MPa}$ (Fig. 2).

For the intergroup comparison post hoc analysis was done ( $p$ value 0.000 ) (Table 1).

Group I-Chitosan solution was significantly different from groups II and III.

Group II-M. citrifolia juice was significantly different from groups I and III.

Group III-EDTA was significantly different from groups I and II.

\section{Discussion}

EDTA is the most frequently used chelating agent. In the present study, 17\% EDTA effectively removed the smear layer that allowed the penetration of the sealer into the open dentinal tubules, hence creating an efficient microretention. Various studies have been done on smear layer removal efficacy with different chelating agents and irrigants. The results of this study with respect to EDTA are similar to the study done by Verma et al. ${ }^{10}$ Madhusudhana et al. reported that there was no statistically significant difference between Chitosan and EDTA in the elimination of the smear layer. ${ }^{9}$ A study proved that $0.2 \%$ Chitosan, $15 \%$ EDTA, and $10 \%$ citric had similar smear layer removal patterns. ${ }^{4}$

A study reported that $1 \mathrm{~mL}$ of $17 \%$ EDTA when used for 1 minute eliminates smear layer effectively. Application of EDTA for more

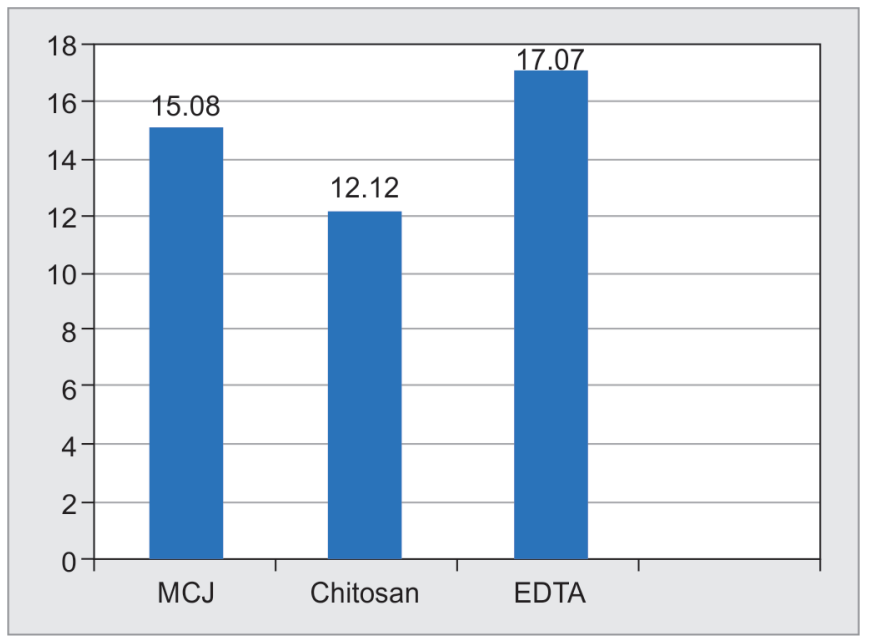

Fig. 2: Mean push-out strength values of EDTA, MCJ, and chitosan 
Table 1: Intergroup comparison of EDTA, MCJ, and chitosan (post hoc analysis)

Multiple comparisons

\begin{tabular}{|c|c|c|c|c|c|c|}
\hline \multicolumn{7}{|c|}{ Dependent variable: mean } \\
\hline \multicolumn{7}{|c|}{ Bonferroni } \\
\hline \multirow[b]{2}{*}{ (I) Group } & \multirow[b]{2}{*}{ (J) Group } & \multirow[b]{2}{*}{ Mean difference (I-J) } & \multirow[b]{2}{*}{ Std. error } & \multirow[b]{2}{*}{$p$ value } & \multicolumn{2}{|c|}{ 95\% confidence interval } \\
\hline & & & & & Lower bound & Upper bound \\
\hline \multirow[t]{2}{*}{$\mathrm{MCH}$} & Chitosan & $2.9643333^{*}$ & 0.4798976 & 0.000 & 1.792831 & 4.135835 \\
\hline & EDTA & $-1.9866667^{*}$ & 0.4798976 & 0.000 & -3.158169 & -0.815165 \\
\hline \multirow[t]{2}{*}{ Chitosan } & $\mathrm{MCH}$ & $-2.9643333^{*}$ & 0.4798976 & 0.000 & -4.135835 & -1.792831 \\
\hline & EDTA & $-4.9510000^{*}$ & 0.4798976 & 0.000 & -6.122502 & -3.779498 \\
\hline \multirow[t]{2}{*}{ EDTA } & $\mathrm{MCH}$ & $1.9866667^{*}$ & 0.4798976 & 0.000 & 0.815165 & 3.158169 \\
\hline & Chitosan & $4.9510000^{*}$ & 0.4798976 & 0.000 & 3.779498 & 6.122502 \\
\hline
\end{tabular}

*The mean difference is significant at the 0.05 level

than 1 minute or the quantity greater than $1 \mathrm{~mL}$ led to the erosion of the root dentin. So, in the current study, $1 \mathrm{~mL}$ of $17 \%$ EDTA was used for 1 minute. ${ }^{11}$ To avoid the bias among all the experimental groups, $1 \mathrm{~mL}$ of the final irrigant was used for 1 minute was used. ${ }^{9}$

Earlier studies have proven $6 \% \mathrm{MCJ}$ and $0.2 \%$ of chitosan have similar chelating action as $17 \%$ EDTA. Hence, these specific concentrations were considered in this study. ${ }^{9}$ Sayin et al. reported that when EDTA was used alone or combination with sodium hypochlorite, it significantly decreased the microhardness of root dentin. ${ }^{12}$ Use of EDTA for 1 minute effectively removes dentinal debris, but when applied for 10 minutes erodes the root dentin. The erosion is because of an extensive opening and broadening of the dentinal tubule. Hence, the application of EDTA longer than 1 minute is not advised. ${ }^{13}$ Thus, to overcome the ill effects of EDTA, more biocompatible irrigants need to be studied.

Morinda citrifolia has been studied in endodontics as an irrigant and intracanal medicament. A study by Madhusudan et al. proved that MCJ group performed better than the chitosan solution group in eliminating the smear layer. M. citrifolia juice acquires antibacterial properties and also contains organic acids such as caproic, caprylic, and ursolic acids. The chelating property of MCJ could be due to the presence of these organic acids. ${ }^{9}$ Studies have reported $6 \%$ $\mathrm{MCJ}$ as an effective chelator without any adverse influence on microhardness property of root dentin compared to EDTA ${ }^{14}$ In this study, MCJ was as effective as EDTA to eliminate the smear layer and has a better push-out bond strength.

Chitosan has an effect on the inorganic portion of the smear layer for its elimination from the root dentin. Chitosan is hydrophilic in nature, which helps it to get adsorbed into the root dentin. Chitosan possess a great number of free hydroxyl and amino groups that make it cationic in nature. ${ }^{15}$ This in return is responsible for the ionic interaction between the dentin calcium ions and the chelator. In an acidic medium, the amino groups present in the polymer are protonated which results in the attraction of other molecules for adsorption to root dentin, which then penetrates deeper in the dentinal tubules. ${ }^{16,17}$ Atomic absorption spectrophotometry with flame analysis was done using of $0.2 \%$ chitosan solution which showed no significant difference compared to 15\% EDTA. If both solutions have a similar chelating effect, then the less concentrated solution should be preferred for use. ${ }^{4}$ In the present study, chitosan was as effective as EDTA and MCJ in elimination of the smear layer, but there was a statistical difference in push-out bond strength.

The ability of the sealer to penetrate into the tubular dentin and thereby adapting the obturating material to the canal walls is much more improved after the removal of the smear layer. AH Plus is an epoxy resin-based root canal sealer. It provides good mechanical properties, high radio opacity, adequate biocompatible properties, mild polymerization shrinkage, low solubility, and microretention to root dentin. ${ }^{10}$

Results of this study showed that EDTA had the highest pushout bond strength when compared to MCJ and chitosan solution. Future studies should be carried out using different concentrations of irrigants at different time intervals and their effect in vivo.

\section{Conclusion}

Within the limits of the study, it can be concluded that chitosan solution and $M$. citrifolia can be used as herbal alternative irrigants as final flush during the cleaning and shaping of the root canals. It is seen that they are effective, less toxic, and more biocompatible than the traditionally used irrigants.

\section{References}

1. Violich DR, Chandler NP. The smear layer in endodontics- a review. Int Endod J 2010;43(1):2-15. DOI: 10.1111/j.1365-2591.2009. 01627.x.

2. Pimenta JA, Zaparolli D, Pecora JD, et al. Chitosan: effect of a new chelating agent on the microhardness of root dentin. Braz Dent J 2012;23(3):212-217. DOI: 10.1590/s0103-64402012000300005.

3. Shokouhinejad N, Hoseini A, Gorjestani $\mathrm{H}$, et al. The effect of different irrigation protocols for smear layer removal on bond strength of a new bioceramic sealer. Iranian Endod J 2013;8(1):10-13.

4. Silva PV, Guedes DF, Nakadi FV, et al. Chitosan: a new solution for removal of smear layer after root canal instrumentation. Int Endod J 2013;46(4):332-338. DOI: 10.1111/j.1365-2591.2012.02119.x.

5. Akncbay H, Senel S, Ay ZY. Application of chitosan gel in the treatment of chronic periodontitis. J Biomed Mater Res Part B, Appl Biomater 2007;80(2):290-296. DOI: 10.1002/jbm.b.30596.

6. Senel S, Ikinci G, Kas S, et al. Chitosan films and hydrogels of chlorehexidinegluconate for oral mucosal delivery. Int J Pharma 2000;193(2):197-203. DOI: 10.1016/s0378-5173(99)00334-8.

7. Ballal NV, Shavi GV, Kumar R, et al. In vitro sustained release of calcium ions and $\mathrm{pH}$ maintenance from different vehicles containing calcium hydroxide. J Endod 2010;36(5):862-866. DOI: 10.1016/j. joen.2009.12.021.

8. Murray PE, Farber RM, Namerow KN, et al. Evaluation of Morinda citrifolia as an endodontic irrigant. J Endod 2008;34(1):66-70. DOI: 10.1016/j.joen.2007.09.016.

9. Madhusudhana K, Satyavathi E, Lavanya A, et al. Comparison of the effect of chitosan and Morinda citrifolia on smear layer removal: an in vitro study. Sch J DentSci 2015;2(2A):132-136. 
10. Verma D, Taneja S, Kumari M. Efficacy of different irrigation regimes on the push-out bond strength of various resin-based sealers at different root levels: an in vitro study. J Conserv Dent 2018;21(2):125-129. DOI: 10.4103/JCD.JCD_337_16.

11. Crumpton BJ, Godell GG, McClanahan SB. Effects on smear layer and debris removal with varying volumes of $17 \%$ REDTA after rotary instrumentation. J Endod 31(7):536-538. DOI: 10.1097/01. don.0000148871.72896.1d.

12. Sayin TC, Serper A, Cehreli ZC, et al. The effect of EDTA, EGTA, EDTAC and tetracycline- $\mathrm{Hcl}$ with and without subsequent $\mathrm{NaOCl}$ treatment on the microhardness of root canal dentin. Oral Surg Oral Med Oral Pathol Oral Radiol Endod 2007;104(3):418-424. DOI: 10.1016/j. tripleo.2007.03.021.

13. Fernández ML, Pérez GG, Villagómez, II MO, et al. Lara in vitro study of erosion caused by EDTA on root canal dentin. 2012;16(1):8-13.
14. Saghiri MA, Garcia-Godoy F, Asgar K, et al. The effect of Morinda citrifolia juice as an endodontic irrigant on smear layer and microhardness of root canal dentin. Oral Science Int 2013;10(2):53-57. DOI: 10.1016/S1348-8643(12)00073-0.

15. Zhang J, Xia W, Liu P, Cheng Q, et al. Chitosan modification and pharmaceutical/biomedical applications. Mar Drugs 2010;8(7): 1962-1987. DOI: 10.3390/md8071962.

16. Shrestha A, Kishen A. The effect of tissue inhibitors on the antibacterial activity of chitosan nanoparticles and photodynamic therapy. J Endod 2012;38(9):1275-1278. DOI: 10.1016/j.joen.2012. 05.006.

17. Rhazi $M$, Desbrières J, Tolaimate $A$, et al. Influence of the nature of the metal ions on the complexation with chitosan. application to the treatment of liquid waste. Eur Polym J 2002;38(8):1523-1530. DOI: 10.1016/S0014-3057(02)00026-5. 